\title{
МЕТОДОЛОГИЯ ФОРМИРОВАНИЯ ФИНАНСОВОЙ ОТЧЕТНОСТИ ОБЪЕДИНЕНИЯ БИЗНЕСОВ
}

\section{METHODOLOGY FOR FORMING FINANCIAL STATEMENTS FOR BUSINESS COMBINATIONS}

I. Epifanov

Summary. The ongoing changes in the modern world economy are determined by the basic prerequisite for the entry of Russian companies into the market of foreign countries, respectively, they require an up-todate solution to the existing problem of adapting domestic reporting and accounting to international rules. Most often, the concepts of business associations are defined on the basis of legally fixed in Russian legislation ideas about the reorganization of a legal entity, the forms of which are mergers and acquisitions. It is worth noting that in fact, in the world and Russian practice, the concept of $M \& A$ covers a much wider range of possible options for conducting transactions than those directly specified in Russian legislation. Due to these features formed and continues to develop sustainable business practices of transactions of this kind, as well as legislative and regulatory framework covering, as proper legislation and accounting standards and accounting, allowing to quickly implement legalization and integration companies, however, requires improvements in the methods of accounting processes of the enterprises business and it improvement should be made to reflect the types of transactions, accompanying this association (which determines the scientific novelty of the article).

Keywords: reporting, financial reporting, international standard, business combination.

\author{
Епифанов Иван Николаевич \\ Аспирант, Финансовый университет при \\ Правительстве РФ \\ epifanov.in@mail.ru
}

Аннотация. Происходящие изменения в современной мировой экономике определяются базовой предпосылкой выхода российских компаний на рынок зарубежных стран, соответственно, они требуют актуального разрешения имеющейся проблемы адаптации отечественной отчетности и учета к международным правилам. Наиболее часто понятия объединения бизнесов определяются на основе юридически закрепленных в российском законодательстве представлениях о реорганизации юридического лица, формами которой являются слияние и присоединение. Стоит отметить, что фактически в мировой и российской практике понятие М\&А охватывает гораздо более широкий спектр возможных вариантов проведения сделок, чем те, что непосредственно указаны в российском законодательстве. Ввиду данных особенностей сформировалась и продолжает развиваться устойчивая деловая практика проведения сделок подобного рода, а также законодательная и нормативная база, охватывающая, как и собственно законодательные нормы, так и стандарты отчетности и учета, позволяющие максимально быстро осуществлять юридическое оформление и интеграцию компаний, однако требуется совершенствование методов отражения в финансовой отчетности процессов объединения бизнесов, и это совершенствование должно быть направлено на то, чтобы отражать виды сделок, сопровождающих это объединение (что определяет научную новизну статьи).

Ключевые слова: отчетность, финансовая отчётность, международный стандарт, объединение бизнесов.

можных в будущем расходов [2]. Нацеленный на спекуляцию в результате объединения бизнеса покупатель не стремится к качественному улучшению приобретаемого бизнеса и приобретает его «as it is», т.е. в том состоянии, в котором находится компания и с теми темпами роста и развития, которые имеет на момент приобретения, поэтому финансовая отчётность важна в любом случае и должна отражать положение дел в максимально объективной степени. Отражение может иметь самые разные дефекты - например, превышение инвестиционной стоимости над справедливой стоимостью обычно называют премией за контроль (control premium) или премией поглощения (acquisition premium).

В целом сделки M\&A (сокр. от англ. Mergers and Acquisitions - слияния и поглощения) - один из эффективных способов увеличения капитала и доли бизнеса, 
привлечения новых клиентов и оптимизации затрат. Таким образом, цена сделки, т.е. сумма средств, уплаченная за целевую компанию, фактически может отклоняться от различных видов определяемой стоимости. Разницу между ценой сделки и рыночной стоимостью называют премией за приобретение, считается, что в случае если цена предложения будет ниже или равна рыночной стоимости компании, компания-цель при прочих равных условиях будет не склонна к проведению сделки.

Стоимость целевой для поглощения компании - это динамически изменяющаяся величина, подверженная влиянию разнообразных факторов. В случае рассмотрения справедливой стоимости, данные факторы можно объединить в две группы: факторы стоимости и факторы риска - которые оказывают разнонаправленное влияние на итоговый показатель. Инвестиционная стоимость компании значительно выше справедливой стоимости, что, в первую очередь, связано с потенциальным получением определенных синергетических эффектов, но, с другой стороны, сопряжено с более высокими рисками, связанными как непосредственно с целевой компанией, так и собственно с проведением сделки. В рамках оценки при объединении бизнесов часть из представленных методов на практике не применяется, например, использование методов дисконтирования чистой прибыли или дивидендных выплат нецелесообразно, т.к. не отражает всей совокупности средств доступных для потенциальных собственников, а метод замещения и метод ликвидационной стоимости часто не применимы, т.к. не отвечают основной цели оценки.

В рамках затратного подхода получили распространение метод скорректированной балансовой стоимости и метод ликвидационной стоимости. В рамках сравнительного подхода рассмотрим два основных метода:

1. Метод публичной компании-аналога;

2. Метод сделок по объединению бизнесов.

При оценке стоимости компаний при объединении бизнесов наибольшее распространение получили методы доходного подхода, т.к. именно они отвечают основным стратегическим мотивам проведения сделок подобного рода - увеличения стоимости объединенного бизнеса за счет эффекта синергии. Разница между денежными потоками объединенного бизнеса и денежными потоками компаний как самостоятельных бизнес-единиц является мерой синергетического эффекта. Компания-покупатель приобретает компанию-цель в данный момент, чтобы получить в будущем прибыль, но эта прибыль даже при адекватно составленной финансовой отчётности не гарантирована, т.е. для них характерны риски, что также находит отражение в методах доходного подхода. Однако необходимо отметить, что на сегодняшний день с учетом ситуации на международ- ном финансовом рынке и наличием кризисных явлений в экономике многих стран максимизация стоимости за счет синергии не является наиболее приоритетным мотивом сделок по слиянию и поглощению. Сделки M\&A в условиях финансового кризиса и в посткризисный период совершаются во многом исходя из «стремления к выживанию», чем крупнее компания, тем легче ей справится с неблагоприятно изменившейся конъюнктурой рынка. Более того, на взгляд автора, любой экономический кризис, как на национальном уровне, так и в глобальном масштабе своим последствием имеет перераспределение ресурсов в экономике, а сделки по слиянию и поглощению представляют собой один из механизмов подобного перераспределения. Таким образом, в период спада экономической активности одни компании обесцениваются, а те, что находятся в более выгодном положении и обладают свободными финансовыми ресурсами, имеют возможность приобрести на выгодных условиях отдельные активы или бизнес в целом. В данных условиях с финансовой точки зрения при оценке стоимости целевой компании особое значение имеет определение максимально достоверных денежных потоков.

Охарактеризуем наиболее часто применяемые методы оценки при объединении бизнесов в рамках доходного подхода. Метод дисконтирования денежных потоков (DCF) является высокоэффективным методом оценки стоимости в случае, если предполагается, что структура капитала фирмы будет неизменной и что она функционирует в относительно стабильной среде, ввиду чего можно с определенной долей точности спрогнозировать показатели ее деятельности в будущем. Существует множество вариаций модели дисконтирования денежных потоков. В рамках оценки при проведении сделок по слиянию и поглощению базовым вариантом является модель дисконтирования чистых (свободных) денежных потоков. На основании выявленных закономерностей составляется прогноз денежных потоков путем моделирования основных показателей финансовой отчетности. Наибольшая сложность при моделировании оценки стоимости компании - составить верный прогноз. Для этого необходимо не только максимально точно определить объем рынка, для чего может быть использована количественная интерпретация факторов стоимости, что позволит учесть все основные параметры, влияющие на денежные потоки компании.

В 90-е гг. XX века были сформулированы и получили широкое распространение методы оценки бизнеса на основе показателей экономической прибыли. Эти методы разрабатывались на базе фундаментальных основ теории дисконтирования денежных потоков и нацелены на преодоление отдельных его недостатков. На базе сравнительного анализа различных подходов и мето- 
дов оценки бизнеса, а также действительной практики оценки компаний в целях слияний и поглощений аудиторско-консалтинговой компанией КПМГ автором разработана собственная комплексная методика оценки компаний телекоммуникационного сектора на этапе исследования финансовой отчётности, предваряющего объединение бизнесов. Далее была проанализирована динамика изменения основных факторов и составлен их прогноз. Прогнозирование факторов осуществляется с позиций консервативного подхода, т.е. предполагается сохранение текущего уровня конкуренции на рынке, темпов роста доли рынка, тенденций изменения основных параметров деятельности.

Показатели операционных расходов и чистых капитальных затрат относительно стабильны за рассматриваемый период, в связи с чем их прогнозирование осуществлялось на основании линейного тренда. Что касается других факторов, то ввиду отсутствия однозначной динамики, прогноз составлялся на основании средних темпом прироста показателя за рассматриваемый период. Специфические риски, выявляемые в ходе проведения исследования финансовой отчётности, предваряющего объединение бизнесов, служат инструментами в том числе для выбора методов отражения положения дел в финансовой отчётности. В рамках исследования финансовой отчётности, предваряющего объединение бизнесов, оценка стоимости является заключающим этапом после оценки финансовых, налоговых, юридических и других рисков. Фактор стоимости представляет собой некую переменную от которой зависит результативность деятельности предприятия.

Среди таких факторов, заметно влияющие на стоимость при объединении бизнесов, стоит выделить качество услуг, восприятие бренда, лояльность клиентов, репутацию компании на рынке. Как и факторы риска, факторы стоимости можно подразделить на макроэкономические, отраслевые и внутренние факторы компании. Макроэкономические факторы определяются макроэкономическим прогнозом развития экономики той территории, на которой оперирует компания. В качестве основных макроэкономических факторов стоит выделить темп роста ВВП, темп роста инфляции, изменение валютных курсов. Макроэкономические и отраслевые факторы формируют внешние условия роста стоимости компании, внутренние факторы - это непосредственно рычаги, воздействуя на которых компания может увеличить свою стоимость. С точки зрения финансового менеджмента, внутренние факторы стоимости поддаются управлению и контролю в рамках операционной (ценообразование, сбыт, продуктовая линейка, маркетинг, реклама), инвестиционной (управление кредиторской задолженностью, капитальные вложения) и финансовой (источники финансирования, дивидендная политика) деятельности путем реализации соответствующих стратегий, что должно быть отражено в финансовой отчётности, предваряющей объединение бизнеса.

Сравнительный анализ показал, что наиболее информативным, репрезентативным и гибким методом отражения ситуации на момент объединения является метод дисконтирования чистых денежных потоков, который позволяет оценивать как справедливую, так и инвестиционную стоимость целевой компании, учитывая факторы стоимости и риска. Метод дисконтирования чистых денежных потоков позволяет учитывать разнообразные факторы, влияющие на стоимость компании непосредственно в составе денежного потока, а также отражает риск инвестирования в выбранный объект в виде применяемой ставки дисконтирования. Наибольшее распространение получила теория повышения добавленной экономической стоимости компании (теория синергии). Несмотря на то, что теория синергии продолжает оставаться основной при объяснении мотивов сделок по корпоративной реструктуризации, стоит отметить, что исследования и практика проводимых сделок показывают, что большинство сделок не достигают тех выгод, которые планируются, и в этом плане «неэффективны», однако компании продолжают использовать данные сделки как основной инструмент своего развития. Это дает право утверждать, что «информационное отражение бизнес-процессов по объединению бизнеса имеет прогнозную ценность» [3].

С изучением слияний и поглощений в мировой и отечественной практике были выделены различные классификации сделок, каждая из которых обладает своей спецификой и отражает тот или иной аспект этих явлений. К основным признакам классификации сделок можно отнести следующие: стратегия покупателя, стоящая за слиянием; статус компаний после слияния; национальная принадлежность объединенных компаний; взаимность намерений покупателя и продавца; способ объединения потенциала; характер слияния. Оценка стоимости также является неотъемлемым элементом непосредственно процесса проведения сделки: в случае, если в сделке участвуют акционерные общества, оценка стоимости проводится для определения коэффициента конвертации акций присоединяемой (поглощаемой) компании в акции образованной компании, либо для определения стоимости выкупа акций

Даже незначительные ошибки и искажения отражения в финансовой отчётности объединения бизнесов способны повлечь за собой серьезные проблемы при осуществлении сделок и сделать недостижимыми намеченные цели. Совершение сделок по слияниям и поглощениям должно отвечать стратегическим ориентирам компании и основной цели функционирования бизнеса, 
а именно максимизации его стоимости. Таким образом, рациональная и максимально объективная оценка бизнеса при проведении слияний и поглощений является залогом эффективности сделки с начальных этапов ее проведения. При этом, несмотря на существующую специфику отечественной деловой среды, важность совершенствования методов отражения в финансовой отчетности объединения бизнесов в целом вызвана объективными причинами.

Методы определения рыночной и справедливой стоимости также схожи, но при этом есть ряд особенностей, которые следует учитывать при их расчете. Представляется, совершенствования методов отражения в финансовой отчетности объединения бизнесов должно быть направлено на то, чтобы отражать, что сделки объединения бизнеса могут иметь следующие основные формы:
- собственно слияние, т.е. создание нового юридического лица в результате объединения поглощаемой и поглощающей компаний;

- поглощение, приобретение контрольного пакета без утраты формальной юридической самостоятельности поглощаемой компании;

- выкуп акций заемными средствами (LBO);

- выкуп акций менеджментом (MBO);

- изменение структуры собственности в виде перераспределения активов между компаниями;

- «обратное слияние»- сделка, при которой частная компания приобретает публичную компанию, акции которой котируются на бирже, и таким образом сама становится публичной, осуществляется в качестве аналога IPO;

- выделение и продажа бизнес-единицы (spin-off);

- банкротство предприятия с последующим приобретением ее активов.

\section{ЛИТЕРАТУРА}

1. МСФ0 (IFRS) 3 «0бъединения бизнесов» (введен в действие Приказом Минфина России от 28.12.2015 № 217н) (ред. от 04.06.2018) // СПС КонсультантПлюс

2. Плотников В.С., Плотникова О.В. Объединение бизнеса и консолидированная финансовая отчетность: Монография. М.: ИНФРА-М, 2018. 278 С.

3. Плотников В.С., Плотникова 0.В. Анализ теоретических основ концепции консолидированной финансовой отчетности // Международный бухгалтерский учет. 2018. № 21-22. С. 1314-1328.

(c) Епифанов Иван Николаевич (epifanov.in@mail.ru ).

Журнал «Современная наука: актуальные проблемы теории и практики»

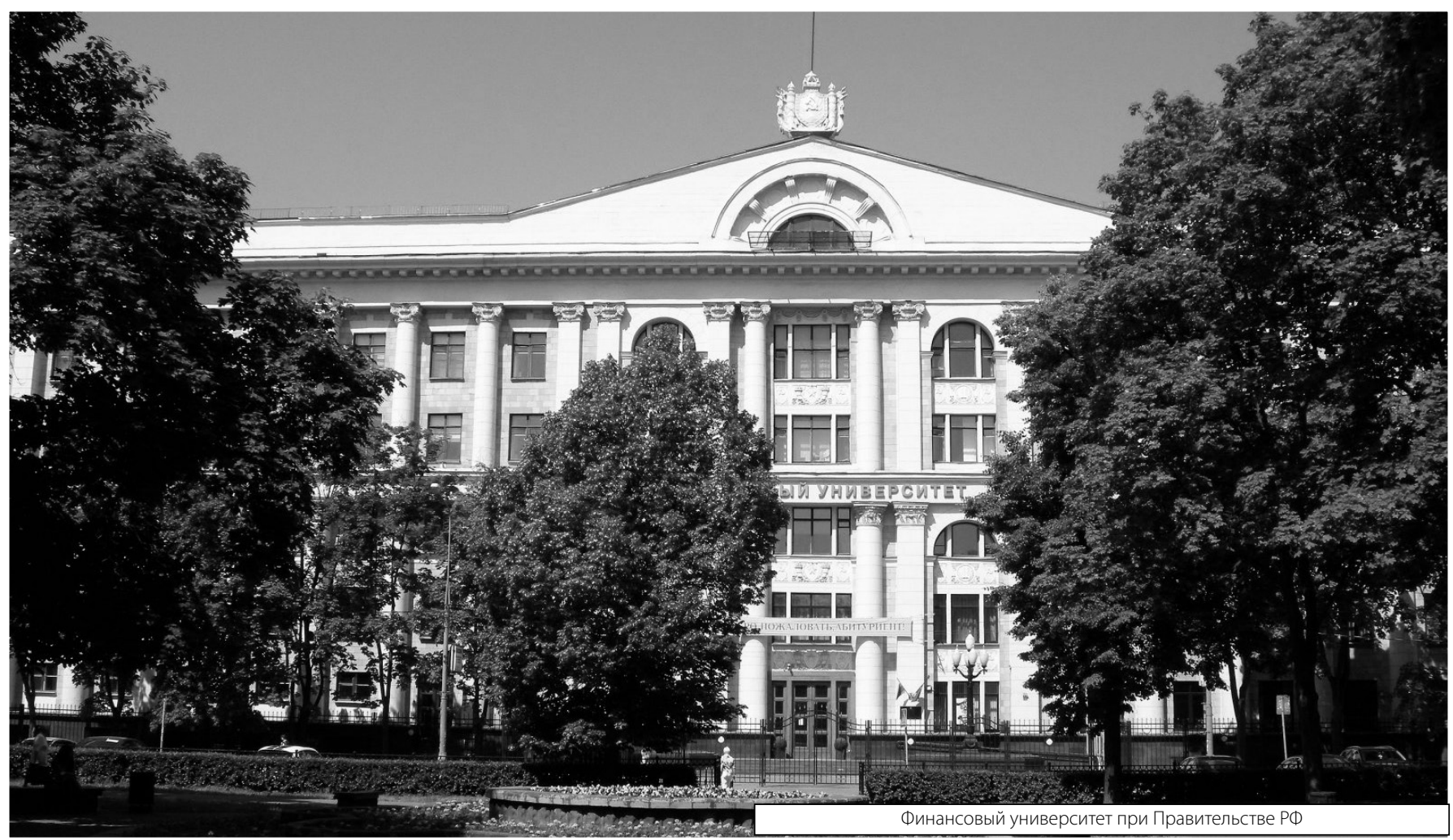

